\title{
VIBRATION CONTROL OF A COLUMN WITH CONCENTRATED MASS BY MEANS OF PIEZOCERAMIC ELEMENTS
}

\author{
Krzysztof Sokót \\ Institute of Mechanics and Machine Design, Czestochowa University of Technology \\ Częstochowa, Poland \\ sokol@imipkm.pcz.pl
}

\begin{abstract}
In this paper, the results of numerical studies on vibration control of a geometrically nonlinear column with additional mass and spring elements are presented. The external load is induced by axially applied force $\mathrm{P}$ with constant line of action. The additional mass element and the spring are placed on different members of the system. The boundary problem has been formulated on the basis of the Hamilton's principle. Due to the geometrical nonlinearity of the investigated system, the solution of the problem was performed by means of the small parameter method. The main purpose of this paper is to investigate the influence of the piezoelectric force on the vibration, divergence instability and critical loading.
\end{abstract}

Keywords: vibration, piezoceramic, instability, vibration control

\section{Introduction}

The piezoceramic elements are widely used in industry and everyday life. They are parts of sensors and activators, medical and sport equipment, fuel injectors, data storage devices and positioning systems. Due to their mechanical features such as Young modulus one can be installed as a part of the mechanical units to control vibration or shape of slender systems.

The studies on vibration and shape control have been performed in recent years. Przybylski and Sokó [1] have investigated the possibility of shape control by means of piezoceramic element discretely attached to the base structure. The same authors have installed the piezoelement as a part of column subjected to the follower loading [2]. The vibration control of beam systems and bridges was investigated and presented by Song et al. [3]. Irschik's [4] investigations on the methods of shape control of the initially deformed system have been presented in the scientific papers.

The study on vibration and instability of slender systems subjected to different types of external loading were performed by many scientists [5-8]. They have investigated the influence of the geometrical and physical features on dynamic behavior of columns and beams. 
In this study the problem of control of vibration and loading capacity of the geometrically nonlinear column consisted of four rods with divergence instability is taken into account. Rods (1) and (2) have a rigid connection while (3) and (4) are joined by a pin and rotational spring. The investigated system is loaded by an external force applied at the free end. The boundary problem of has been formulated by means of Hamilton's principle [9] and solved according to small parameter method [10].

\section{Formulation of the problem}

In Figure 1 the investigated nonlinear cantilever column is presented. The first and the second rod have a rigid connection. In the point of this connection concentrated mass has been placed. Rods three and four have a flexible connection which is being simulated by a pin, strengthened by a rotational spring with stiffness $C$. The column is loaded by external force $P$ with constant line of action placed on the free end of the system. Rods have a length $l_{1}, l_{2}, l_{3}, l_{4}$. The investigated system can be presented as a column composed of two coaxial tubes, tube and rod or can be a flat frame. For the more general problem formulation at this stage the piezoceramic rod is not indicated.

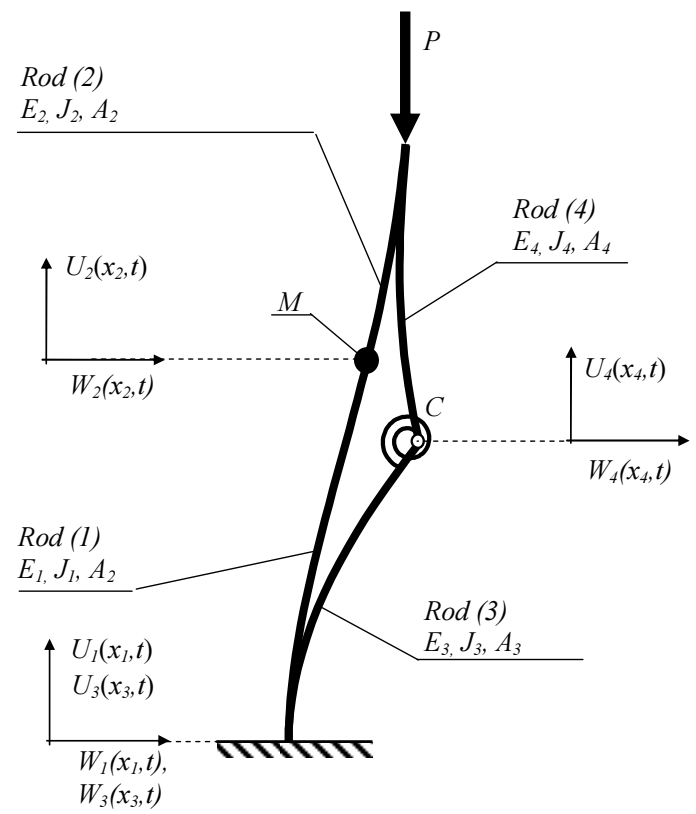

Fig. 1. The nonlinear system under consideration subjected to generalized load

The problem presented in this paper has been formulated by means of Hamilton's principle: 


$$
\delta \int_{t_{1}}^{t_{2}}(T-V) d t=0
$$

The kinetic $T$ and potential $V$ energy are expressed as follows:

$$
\begin{gathered}
T=\frac{1}{2} \sum_{i=1}^{4} \int_{0}^{l_{i}} \rho_{i} A_{i}\left(\frac{\partial W_{i}\left(x_{i}, t\right)}{\partial t}\right)^{2} d x_{i}+\frac{1}{2} M\left(\frac{\partial W_{1}\left(x_{1}, t\right)}{\partial t}\right)_{x_{1}=l_{1}}^{2}+ \\
+J m\left(\frac{\partial^{2} W_{1}\left(x_{1}, t\right)}{\partial x \partial t}\right)_{x_{1}=l_{1}}^{2} \\
V=\frac{1}{2}\left\{\left[\sum_{i=1}^{4} \int_{0}^{l_{i}} E_{i} J_{i}\left[\frac{\partial^{2} W_{i}\left(x_{i}, t\right)}{\partial x_{i}^{2}}\right]^{2} d x_{i}+\int_{0}^{l_{i}} E_{i} A_{i}\left[\frac{\partial U_{i}\left(x_{i}, t\right)}{\partial x_{i}}+\frac{1}{2}\left(\frac{\partial W_{i}\left(x_{i}, t\right)}{\partial x_{i}}\right)^{2}\right]^{2} d x_{i}\right\}+\right. \\
+\frac{1}{2} C\left(\left.\frac{\partial W_{4}\left(x_{4}, t\right)}{\partial x_{4}}\right|_{x_{4}=0}-\left.\frac{\partial W_{3}\left(x_{3}, t\right)}{\partial x_{3}}\right|_{x_{3}=l_{3}}\right)^{2}+P U_{2}\left(l_{2}, t\right)
\end{gathered}
$$

The kinetic (2) and potential (3) energy being introduced into (1) and after completing the variational and integration operations, and knowing that virtual: longitudinal $\delta U_{i}\left(x_{i}, t\right)$ and transversal $\delta W_{i}\left(x_{i}, t\right)$ displacements $(i=1,2,3,4)$ are arbitrary and independent for $0<x_{\mathrm{i}}<l_{\mathrm{i}}$ the equations were obtained:

$E_{i} J_{i} \frac{\partial^{4} W_{i}\left(x_{i}, t\right)}{\partial x_{i}^{4}}-E_{i} A_{i} \frac{\partial}{\partial x_{i}}\left[\left[\frac{\partial U_{i}\left(x_{i}, t\right)}{\partial x_{i}}+\frac{1}{2}\left(\frac{\partial W_{i}\left(x_{i}, t\right)}{\partial x_{i}}\right)^{2}\right] \frac{\partial W_{i}\left(x_{i}, t\right)}{\partial x_{i}}\right]+\rho_{i} A_{i} \frac{\partial^{2} W_{i}\left(x_{i}, t\right)}{\partial t^{2}}=0$

$$
i=1,2,3,4
$$

The axial compressive force is expressed as:

$$
S_{i}(t)=-E_{i} A_{i}\left(\frac{\partial U_{i}\left(x_{i}, t\right)}{\partial x_{i}}+\frac{1}{2}\left[\frac{\partial W_{i}\left(x_{i}, t\right)}{\partial x_{i}}\right]^{2}\right), i=1,2,3,4
$$

The longitudinal displacements are as follows:

$$
U_{i}\left(x_{i}, t\right)=-\frac{S_{i}(t) x_{i}}{E_{i} A_{i}}-\frac{1}{2} \int_{0}^{x_{i}}\left[\frac{\partial W_{i}\left(x_{i}, t\right)}{\partial x_{i}}\right]^{2} d x_{i}, i=1,2,3,4
$$

The investigated system can be described by the set of the geometrical boundary conditions in the form: 


$$
\begin{array}{ll}
\left.W_{1}\left(x_{1}, t\right)\right|_{x_{1}=0}=\left.W_{1}^{I}\left(x_{1}, t\right)\right|_{x_{1}=0}=0 & \left.W_{3}\left(x_{3}, t\right)\right|_{x_{3}=0}=\left.W_{3}^{I}\left(x_{3}, t\right)\right|_{x_{3}=0}=0 \\
\left.W_{2}^{I}\left(x_{2}, t\right)\right|_{x_{2}=l_{2}}=\left.W_{4}^{I}\left(x_{4}, t\right)\right|_{x_{4}=l_{4}} & \left.W_{3}\left(x_{3}, t\right)\right|_{x_{3}=l_{3}}=\left.W_{4}\left(x_{4}, t\right)\right|_{x_{4}=0} \\
\left.W_{1}\left(x_{1}, t\right)\right|_{x_{1}=l_{1}}=\left.W_{2}\left(x_{2}, t\right)\right|_{x_{2}=0} & \left.W_{2}\left(x_{2}, t\right)\right|_{x_{2}=l_{2}}=\left.W_{4}\left(x_{4}, t\right)\right|_{x_{4}=l_{4}} \\
U_{1}(0, t)=U_{3}(0, t)=0 & U_{2}(0, t)=U_{1}\left(l_{1}, t\right) \\
U_{2}\left(l_{2}, t\right)=U_{4}\left(l_{4}, t\right) & U_{4}(0, t)=U_{3}\left(l_{3}, t\right)
\end{array}
$$

On the basis of (7a-m) and the variational equation, the additional set of natural boundary conditions has been obtained:

$$
\begin{gathered}
\left.E_{2} J_{2} W_{2}^{I I}\left(x_{2}, t\right)\right|_{x_{2}=l_{2}}+\left.E_{4} J_{4} W_{4}^{I I}\left(x_{4}, t\right)\right|_{x_{4}=l_{4}}=0 \\
\left.E_{2} J_{2} W_{2}^{I I I}\left(x_{2}, t\right)\right|_{x_{2}=l_{2}}+\left.P W_{2}^{I}\left(x_{2}, t\right)\right|_{x_{2}=l_{2}}+\left.E_{4} J_{4} W_{4}^{I I I}\left(x_{4}, t\right)\right|_{x_{4}=l_{4}}=0 \\
\left.E_{3} J_{3} W_{3}^{I I I}\left(x_{3}, t\right)\right|_{x_{3}=l_{3}}+\left.S_{3} W_{3}^{I}\left(x_{3}, t\right)\right|_{x_{3}=l_{3}}+ \\
-\left.E_{4} J_{4} W_{4}^{I I I}\left(x_{4}, t\right)\right|_{x_{4}=0}-\left.S_{4} W_{4}^{I}\left(x_{4}, t\right)\right|_{x_{4}=0}=0 \\
-\left.E_{4} J_{4} W_{4}^{I I}\left(x_{4}, t\right)\right|_{x_{4}=0}+C\left[\left.W_{4}^{I}\left(x_{4}, t\right)\right|_{x_{4}=0}-\left.W_{3}^{I}\left(x_{3}, t\right)\right|_{x_{3}=l_{3}}\right]=0 \\
\left.E_{1} J_{1} W_{1}^{I I I}\left(x_{1}, t\right)\right|_{x_{1}=l_{1}}+\left.S_{1} W_{1}^{I}\left(x_{1}, t\right)\right|_{x_{1}=l_{1}}-\left.E_{2} J_{2} W_{2}^{I I I}\left(x_{2}, t\right)\right|_{x_{2}=0}-\left.S_{2} W_{2}^{I}\left(x_{2}, t\right)\right|_{x_{2}=0}+ \\
-\left.m \ddot{W}_{1}\left(x_{1}, t\right)\right|_{x_{1}=l_{1}}=0 \\
\left.E_{1} J_{1} W_{1}^{I I}\left(x_{1}, t\right)\right|_{x_{1}=l_{1}}-\left.E_{2} J_{2} W_{2}^{I I}\left(x_{2}, t\right)\right|_{x_{2}=0}+J m \frac{\partial^{3} W_{1}\left(l_{1}, t\right)}{\partial x \partial t^{2}}=0 \\
\left.E_{3} J_{3} W_{3}^{I I}\left(x_{3}, t\right)\right|_{x_{3}=l_{3}}-C\left[\left.W_{4}^{I}\left(x_{4}, t\right)\right|_{x_{4}=0}-\left.W_{3}^{I}\left(x_{3}, t\right)\right|_{x_{3}=l_{3}}\right]=0 \\
S_{3}=S_{4} \quad S_{1}=S_{2} \quad P=S_{1}+S_{3}
\end{gathered}
$$

In the boundary conditions the Roman numerals determine the derivatives with respect to space variable $x_{i}$ and the dots the derivatives with respect to time $t$.

Due to geometrical nonlinearities the small parameter method [10] has been used to solve the boundary. For the column vibrating around the rectilinear form of static equilibrium the longitudinal and transversal displacements, axial force and vibration frequency of rods are being written in a power series according to (9a-d):

$$
\begin{array}{ll}
w_{i}(\xi, \tau)=\sum_{n=1}^{N} \varepsilon^{2 n-1} w_{i 2 n-1}(\xi, \tau)+O\left(\varepsilon^{2 N+1}\right) & u_{i}(\xi, \tau)=u_{i 0}(\xi)+\sum_{n=1}^{N} \varepsilon^{2 n} u_{i 2 n}(\xi, \tau)+O\left(\varepsilon^{2 N+1}\right) \\
k_{i}(\tau)=k_{i o}+\sum_{n=1}^{N} \varepsilon^{2 n} k_{i 2 n}(\tau)+O\left(\varepsilon^{2 N+1}\right) & \omega_{i}^{2}=\omega_{0 i}{ }^{2}+\sum_{n=1}^{N} \varepsilon^{2 n} \omega_{i 2 n}{ }^{2}+O\left(\varepsilon^{2 N+1}\right)
\end{array}
$$

The solution presented in this paper was obtained on the basis of a system of equations with a small parameter in the first power. 


\section{Control of dynamic behaviour by means of piezoceramic element}

Due to general problem formulation, each rod can be treated as made of piezoceramic material. The production of long piezoelements is very complicated and expensive, that is why in further investigation rod (3) will be made of piezoceramic material (see Fig. 1). Currently produced piezoelements are in the form of stacks which are able to induce great loads with relatively small displacements. The constitutive equation of piezoceramic material polarized in the perpendicular direction to the axis of the rod (3) are:

$$
\begin{aligned}
& \stackrel{(3)}{\sigma_{x}}=E_{3} \stackrel{(3)}{\varepsilon_{x}}-e_{31} E_{z} \\
& D_{z}=e_{31} \stackrel{(3)}{\varepsilon_{x}}+\xi_{33} E_{z}
\end{aligned}
$$

( $D_{\mathrm{z}}[\mathrm{m}]$ - displacement induced by electrical field $E_{\mathrm{z}}[\mathrm{V} / \mathrm{m}]$, the $e_{31}$ is a dielectric constant $\left[\mathrm{C} / \mathrm{m}^{2}\right], \xi_{33}$ - effective coefficient of dielectric medium $\left.[\mathrm{C} / \mathrm{Vm}]\right)$.

The strain - displacement relation for the rectilinear form of the static equilibrium of the column when the electric field is being applied, is as follows:

$$
\varepsilon_{x}=\frac{d U_{i}\left(x_{i}\right)}{d x_{i}}
$$

The piezoforce generated by rod (3) can be obtained on the basis of the principle of total potential energy in the form:

$$
\mathrm{E}^{p}=\frac{1}{2} \sum_{i=1}^{3} \int_{\Omega_{i}}^{(i)} \sigma_{x}^{(i)} \varepsilon_{x} d \Omega_{i}-\frac{1}{2} \int_{\Omega_{2}} D_{z} E_{z} d \Omega_{2}
$$

the normal stress in rods $(1,2,4)$ are formulated on the basis of Hooke's law:

$$
\stackrel{(i)}{\sigma_{x}}=E_{i} \dot{(i)}_{x} \quad i=1,2,4
$$

After introducing $(10 \mathrm{a}, 10 \mathrm{~b}, 11,13)$ into (12) and performing mathematical operations it leads to:

$$
\delta \mathrm{E}^{p}=\sum_{i=1}^{3} E_{i} A_{i}\left[\left.\frac{d U_{i}\left(x_{i}\right)_{i}}{d x_{i}} \delta U_{i}\left(x_{i}\right)\right|_{0} ^{l_{i}}-\int_{0}^{l_{i}} \frac{d^{2} U_{i}\left(x_{i}\right)}{d x_{i}^{2}} \delta U_{i}\left(x_{i}\right) d x_{i}\right]-\left.F \delta U_{2}\left(x_{2}\right)\right|_{0} ^{l_{2}}=0
$$

where $A_{i}=b_{i} h_{i}$ and stands for piezoelectric force ( $b$ is a width of the piezoelement). 
On the basis of (14) the four second-order differential equations of longitudinal displacements were obtained:

$$
\frac{d^{2} U_{i}\left(x_{i}\right)}{d x_{i}^{2}}=0, i=1,2,3,4
$$

The geometrical boundary conditions and natural ones are as follows:

$$
\begin{aligned}
& U_{1}(0)=U_{3}(0)=0 \quad U_{1}\left(l_{1}\right)=U_{2}(0) \quad U_{3}\left(l_{3}\right)=U_{4}(0) \\
& \left.E_{2} A_{2} \frac{d U_{2}\left(x_{2}\right)}{d x_{2}}\right|_{x_{2}=l_{2}}+\left.E_{4} A_{4} \frac{d U_{4}\left(x_{4}\right)}{d x_{4}}\right|_{x_{4}=l_{4}}=0 \quad U_{2}\left(l_{2}\right)=U_{4}\left(l_{4}\right) \\
& \left.E_{1} A_{1} \frac{d U_{1}\left(x_{1}\right)}{d x_{1}}\right|_{x_{1}=l_{1}}-\left.E_{2} A_{2} \frac{d U_{2}\left(x_{2}\right)}{d x_{2}}\right|_{x_{2}=l_{2}}=0 \\
& \left.E_{3} A_{3} \frac{d U_{3}\left(x_{3}\right)}{d x_{3}}\right|_{x_{3}=l_{3}}+\left.E_{4} A_{4} \frac{d U_{4}\left(x_{4}\right)}{d x_{4}}\right|_{x_{4}=l_{4}}-F=0
\end{aligned}
$$

The solution of (15) with (16a-g) leads to equations of piezo (residual) forces in each segment

$$
\begin{aligned}
& \left|R_{1}\right|=\left|R_{2}\right|=\left|R_{3}\right|=\left|R_{4}\right|=|R|=F E_{2} A_{2} E_{4} A_{4} l_{3}\left(E_{2} A_{2} E_{3} A_{3} E_{4} A_{4} l_{1}+E_{1} A_{1} E_{3} A_{3} E_{4} A_{4} l_{2}+\right. \\
& \left.+E_{1} A_{1} E_{2} A_{2} E_{4} A_{4} l_{3}+E_{1} A_{1} E_{2} A_{2} E_{3} A_{3} l_{4}\right)^{-1}
\end{aligned}
$$

The force $R$ causes compression or tension which depends on electrical field vector and must be introduced into equations of motion:

$$
E_{i} J_{i} W_{i}^{I V}\left(x_{i}, t\right)+\left(S_{i} \pm R\right) W_{i}^{I I}\left(x_{i}, t\right)+\rho_{i} A_{i} \ddot{W}_{i}\left(x_{i}, t\right)=0, \mathrm{i}=1,2,3,4
$$

The residual force will have an influence on vibration frequency and critical load of the investigated system.

\section{Results of numerical calculations}

Results of numerical calculations on vibration control are presented in the figures below. For a more general purpose the results are presented in the non-dimensional form (see the nomenclature).

In the Figures 2 and 3 an influence of the rotational spring stiffness $c$ has been presented on the plane external load $p$ vs. vibration frequency $\omega$. For small magnitudes of $c$ the vibration frequency and critical loading of the investigated column are the lowest. With the increasing stiffness of $c$ parameter the vibration frequency and critical loading are rising. If $c$ tends to infinity the critical loading is being 
stabilized on the level of $p_{c r}=2.4649$. The dynamic behaviour of the investigated system is highly dependent on the stiffness of connection between rods (3) and (4).

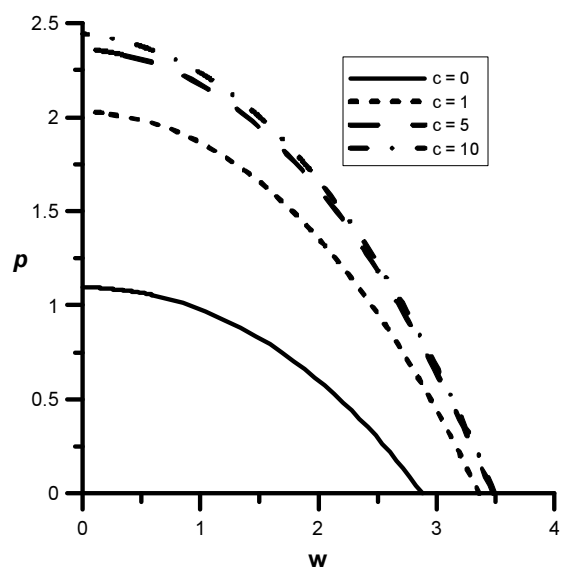

Fig. 2. External load vs. vibration frequency for different spring stiffness $\left(d_{2}=0.5\right.$, $\left.d_{3}=0.5, r_{m}=1, r_{w}=1, m=f=0\right)$

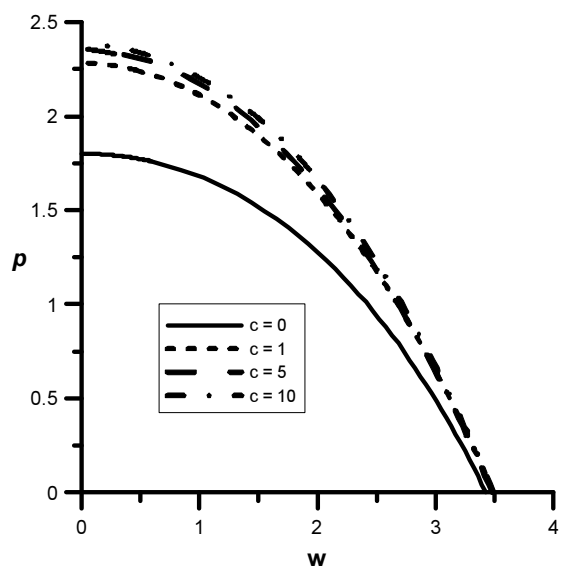

Fig. 3. External load vs. vibration frequency for different spring stiffness $\left(d_{2}=0.5\right.$, $\left.d_{3}=0.7, r_{m}=1, r_{w}=1, m=f=0\right)$

In Figures 4 and 5 an influence of the concentrated mass $m$ have been presented for different spring stiffness and location $\left(c=1,10 ; d_{3}=0.5,0.7\right)$.

The continuous curves refer to the column without mass $m$. In this configuration the highest magnitude of vibration frequency has been obtained. With the increasing magnitude of mass $m$ the reduction of natural vibration frequency can be observed irrespective of spring stiffness. It can be concluded that mass $m$ affects vibration frequency while the magnitude of critical loading stays unchanged for every system configuration.

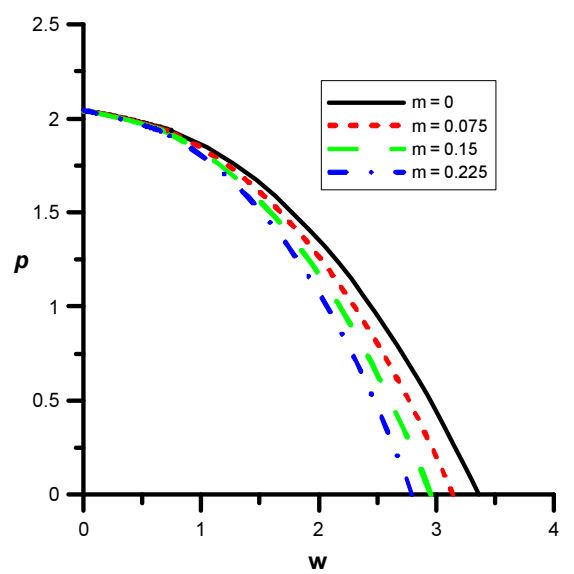

Fig. 4. External load vs. vibration frequency for different mass magnitude $\left(d_{2}=d_{3}=0.5\right.$, $\left.r_{m}=1, r_{w}=1, c=1, f=0\right)$

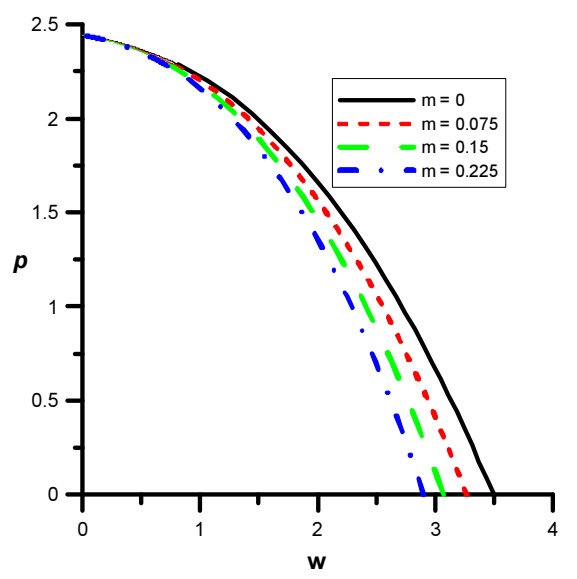

Fig. 5. External load vs. vibration frequency for different mass magnitude $\left(d_{2}=d_{3}=0.5\right.$, $\left.r_{m}=1, r_{w}=1, c=10, f=0\right)$ 
After the series of numerical calculations it has been stated that if the spring stiffens tends to infinity the critical loading is constant and change in $d_{3}$ parameter has no influence on investigated factor. The reduction of spring stiffness results in a decrease in critical loading. The critical loading is stabilizing with the approach to the free end by the pin.

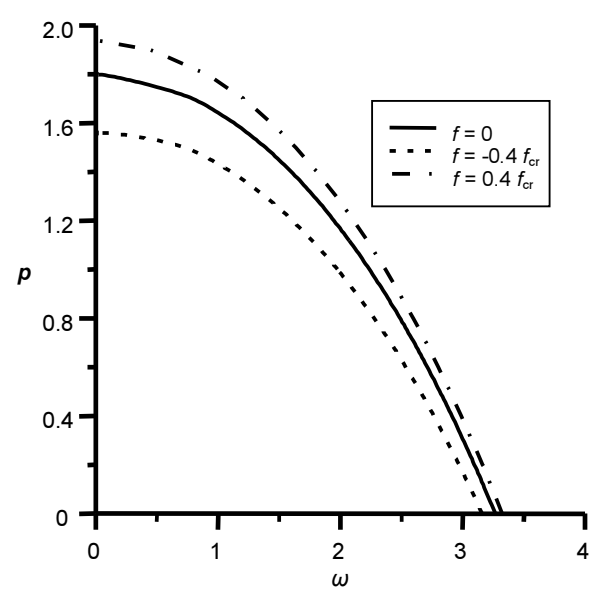

Fig. 6. External load vs. vibration frequency for different magnitude of piezoelectric force $\left(d_{2}=d_{3}=0.5, r_{m}=r_{w}=1, c=0.5, m=0\right)$

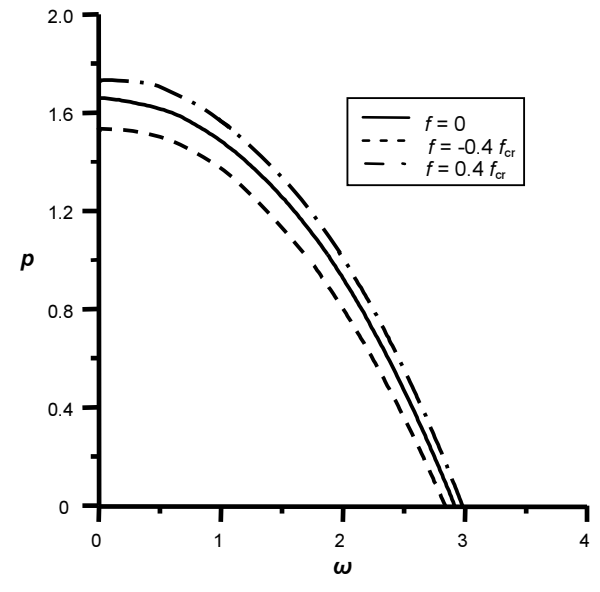

Fig. 7. External load vs. vibration frequency for different mass magnitude $\left(d_{2}=0.5\right.$, $\left.d_{3}=0.3, r_{m}=r_{w}=1, c=0.5, m=0.025\right)$

An influence of the piezoelectric force on the vibration and critical loading has been shown in the Figures 6 and 7. The direction of the electric field vector allows one to control vibration frequency and critical loading of a system regardless of magnitude of $m$ parameter. If the effect of those changes causes compression of the first member (rods (1) and (2)) the critical loading and vibration frequency are rising. The rotational spring stiffness has a great influence on the area of control. If $c$ tends to infinity the applied voltage to the piezoelement regardless to direction of the electric field vector causes the reduction of the investigated parameter of the column. The boundary magnitude of $c$ can be set. This boundary magnitude depends on geometrical features of the system and can not be generalized.

\section{Conclusions}

In this paper the influence of the piezoelectric force on natural vibration frequency and instability of the geometrically nonlinear column subjected to external load with constant line of action has been presented. It can be concluded that:

- mass $m$ has no influence on vibration modes and critical loading,

- rotational spring stiffness affects vibration frequency and critical loading,

- generation of piezoelectric force by means of application of voltage to the piezoelement allows one to control vibration frequency and critical loading, 
- if the piezoforce causes compression of the first member (rod (1) and (2)) an increase of loading capacity as well as vibration frequency have been obtained,

- piezoelectric force allows one to control an instability of the slender system, an area of control depends on geometrical features of the system.

\section{References}

[1] Przybylski J., Sokół K., Shape control of an eccentrically loaded column by means of a piezoceramic rod, Thin-Walled Structures 2011, 49, 5, 652-659.

[2] Przybylski J., Sokół K., Zagadnienie sterowania niestatecznością dywergencyjną i flatterową układu geometrycznie nieliniowego generowaną siłą piezoelektryczną, [in:] Drgania swobodne i stateczność układów smukłych poddanych obciążeniu konserwatywnemu lub niekonserwatywnemu, pr. zbior. pod kierunkiem i red. Lecha Tomskiego, Rozdz. 10, WN PWN, Warszawa 2012, 249-283.

[3] Song G., Sethi V., Li H.-N., Vibration control of civil structures using piezoceramic smart materials: A review, Engineering Structures 2006, 28(11), 1513-1524.

[4] Irschik H., A review on static and dynamic shape control of structures by piezoelectric actuation, Engineering Structures 2002, 24(1), 5-11.

[5] Tomski L., Uzny S., Free vibrations and stability of a geometrically nonlinear column loaded by a follower force directed towards the positive pole, International Journal of Solids and Structures 2008, 45, 87-112.

[6] Uzny S., An elastically supported geometrically nonlinear slender system subjected to a specific load in respect of bifurcation load and free vibrations, International Journal of Bifurcation and Chaos 2011, 21, 10, 2983-2992.

[7] Kukla S., Free vibration and stability of stepped columns with cracks, Journal of Sound and Vibration 2009, 319, 3-5, 1301-1311.

[8] Wang C.Y., Buckling of an internally hinged column with an elastic support, Engineering Structures 2002, 24, 1357-1360.

[9] Skalmierski B., Mechanika, PWN, Warszawa 1982.

[10] Osiński Z., Teoria drgań, PWN, Warszawa 1978.

\section{Nomenclature}

\begin{tabular}{|c|l|c|l|}
\hline$A_{i}$ & Cross section area & $r_{m}$ & Bending stiffness ratio $E_{1} J_{1} / E_{2} J_{2}$ \\
\hline$E_{i}$ & Young's modulus & $r_{w}$ & Bending stiffness ratio $E_{3} J_{3} / E_{4} J_{4}$ \\
\hline$J_{i}$ & Area moment of inertia & $k_{i}$ & Non-dimensional axial force $S_{i} l^{2} / E_{i} J_{i}$ \\
\hline$J_{m}$ & Mass moment of inertia & $m$ & Non-dimensional mass $\mathrm{M} / \rho A l$ \\
\hline$P$ & External force & $w_{i}$ & Non-dimensional transversal displacement $W_{i} / l$ \\
\hline$C$ & Rotational spring stiffness & $u_{i}$ & Non-dimensional axial displacement $U_{i} / l$ \\
\hline$U_{i}$ & Axial displacement & $d_{i}$ & Non-dimensional length of a rod $l_{i} / l$ \\
\hline$W_{i}$ & Transversal displacement & $\xi_{i,} \tau$ & Non-dimensional space and time variable, respectively \\
\hline$M$ & Concentrated mass & $c$ & Non-dimensional spring stiffness $C l /\left(E_{3} J_{3}+E_{4} J_{4}\right)$ \\
\hline$\rho_{i}$ & Density of a material & $\omega_{i}^{2}$ & Non-dimensional natural frequency $\Omega^{2}\left(\rho_{i} A_{i} l^{4} / E_{i} J_{i}\right)$ \\
\hline$\Omega_{i}$ & Natural vibration frequency & $p$ & Non-dimensional external load $P l^{2} /\left(E_{1} J_{1}+E_{2} J_{2}\right)$ \\
\hline$R$ & Piezoelectric force & $f$ & Non-dimensional piezoelectric force $R l^{2} /\left(E_{1} J_{1}+E_{2} J_{2}\right)$ \\
\hline
\end{tabular}

